\title{
Erratum to: Portuguese agriculture and the evolution of greenhouse gas emissions - can vegetables control livestock emissions?
}

\author{
Paulo Reis Mourao ${ }^{1}$ - Vítor Domingues Martinho ${ }^{2}$
}

(C) Springer-Verlag GmbH Germany 2017

Erratum to: Environ Sci Pollut Res (2017) 24:16107-16119

DOI 10.1007/s11356-017-9257-1

This work was carried out within the funding with COMPETE reference ${ }^{\circ}$ POCI-01-0145-FEDER-006683, with the FCT/ MEC's (Fundação para a Ciência e a Tecnologia, I.P.) financial support through national funding and by the ERDF through the Operational Programme on "Competitiveness and Internationalization - COMPETE 2020 under the PT2020 Partnership Agreement

The online version of the original article can be found at http://dx.doi.org/ 10.1007/s11356-017-9257-1

Vítor Domingues Martinho

vdmartinho@esav.ipv.pt

Paulo Reis Mourao

paulom@eeg.uminho.pt

1 Department Economics \& NIPE, University of Minho,

4700 Braga, Portugal

2 Agricultural School, Polytechnic Institute of Viseu,

3500 Viseu, Portugal 